\title{
Labial Verruca Vulgaris: A Case Report and Review of the Literature
}

\author{
Adel Bouguezzi ${ }^{* 1.2}$, Nouha Dammak ${ }^{1.2}$, Chokri Abdellatif ${ }^{1.2}$, Sameh Sioud $^{1.2}$, Hajer Hentati ${ }^{1.2}$, \\ Jemil Selmi ${ }^{1.2}$ \\ ${ }^{1}$ University of Monastir, Faculty of Dental Medicine, Oral Health and Oro-Facial Rehabilitation \\ Laboratory Research (LR12ES11), Monastir, Tunisia \\ ${ }^{2}$ Dental Clinic of Monastir, Department of Medicine and Oral Surgery, Monastir, Tunisia \\ *Corresponding Author: Adel Bouguezzi, University of Monastir, Faculty of Dental Medicine, Oral \\ Health and Oro-Facial Rehabilitation Laboratory Research (LR12ES11), Monastir, Tunisia
}

\begin{abstract}
Verruca vulgaris also known as common warts is a benign lesion of skin and mucous membrane caused by human papilloma virus. Intraoral warts can occur at any age but are most commonly seen in age group of 30-50 years with equal incidence in both genders. A rare case of verruca vulgaris of the lip occurring in a 36-year-old male is presented with a discussion on etiopathogenesis and the treatment methods. Verruca vulgaris must be remembered in the differential diagnosis of lip lesions and surgical treatment may provide satisfactory outcomes.
\end{abstract}

Keywords: Human papilloma virus, papillary lesions, verruca vulgaris.

\section{INTRODUCTION}

Verruca vulgaris (VV) is a frequent skin disease caused by human papillomavirus (HPV) infection [1]. It is also known as common warts and the lesion tends to affect epithelial tissues and mucous membranes. Verruca vulgaris is a benign epidermal proliferation with infrequent malignant change [2]. The clinical presentations of verruca vulgaris vary according to the viral type and the anatomical site infected. The benign VV include squamous papilloma with verruca vulgaris, focal epithelial hyperplasia and condyloma [1]. Verruca vulgaris is most commonly induced by HPV-2, HPV-4 or HPV40 and it rarely occurs on the lip.

\section{OBSERVATION}

A 23-year-old male presented to the Department with complaint of growth on the rightlower labial mucosa since for the past 08 months which was gradually increasing in size, nontender and was not associated with any symptoms.

On examination, a solitary proliferative verrucous growth over the labial mucosa was seen. The lesion was exophytic and sessile in nature, with irregular margins. Surface of the lesion was irregular at the periphery with finger-like projections in the center. The color was white and soft in consistency [Figure 1]. The surrounding mucosa appeared normal. There was no any other such lesion in oral cavity, but on extraoral examination, there was multiple white lesions on the fingers [Figure 2]. No cervical lymph nodes were palpable. The patient had a history of smoking. A provisional diagnosis of verruca vulgaris was made.

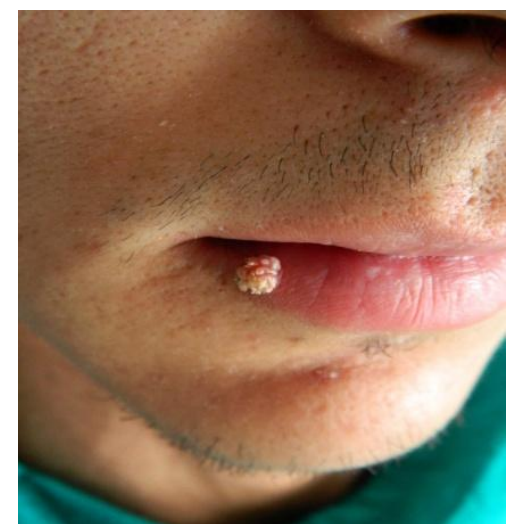

Figure1. White verrucous lesion on the right side of the lower lip 


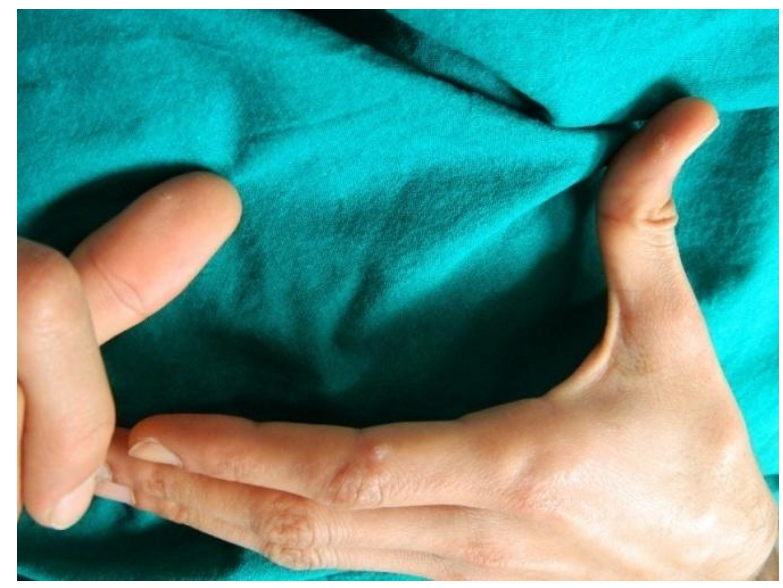

Figure2. Multiple white lesions on the hands

Under local anesthesia, surgical excision with safe margins in aseptic precautions was carried [Figure 3] and sent for histopathological examination. The patient was advised to get an HPV DNA by polymerase chain reaction which was found to be positive.

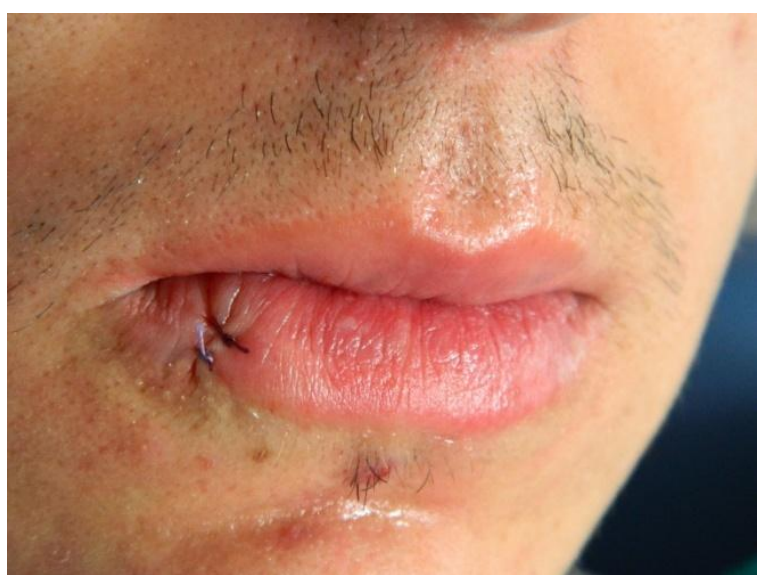

Figure3. Postoperative clinical photograph immediately after excision

Histopathological examination showed long, thin, and finger-like projections lined by stratified squamous epithelium with thin central connective tissue. The epithelium showed areas of parakeratosis with identification of koilocytes, with perinuclear cytoplasmic halos, and irregular hyperchromatic nuclei. The clinical and patho-histological observation all confirm the diagnosis of oral verruca vulgaris.

On follow up of two weeks patient was completely asymptomatic, and no recurrence had been seen at the 1-year follow-up.

\section{DISCUSSION}

Most of the benign epithelial tumours of the oral mucosa have a viral background, caused by DNA-viruses such as the human papilloma viruses. Several types of human papilloma viruses have been described in the past. Verruci form lesions (verruca vulgaris), the condyllomaacuminatum and epithelial hyperplasia or Heck's disease $[3,4,5]$ also belong to this category. Verrucae vulgaris are usually found on hands and fingers. In the mouth they are mostly found on the lips and in the palatal area. Self-inoculation explaines the muco-cutaneous appearance.

More than 100 different types of HPV have been classified and they are divided into high and low oncogenic risk genotypes, depending on the association with malignant change. The viral products stimulate cell growth in the basal layer leading to formation of a common wart. Since the recognition of high-risk $\mathrm{HPVs}$ in oral carcinomas, the malignant potential of HPV infection has been suggested.[6] Potential vaccines have been developed which helps in preventing HPV 16 and 18 infections. These vaccines reduce the risk of developing cancerous or precancerous changes.[7] Entities such as oral lichen planus, lupus vulgaris, and squamous cell carcinoma should be considered as the differential diagnosis.

Verruca vulgaris is most commonly induced by HPV-2, HPV-4 or HPV-40. Its association with $\mathrm{HPV}$ has raised questions about its association 
with oral squamous cell carcinoma. The resulting growth in most of the cases eventually disappears after a year or two even if left untreated. Hence exact role of the virus in the etiopathogenesis of these lesions is yet unclear. $[8,9,10]$.

Various treatment modalities are available ranging from topical agents such as salicylic acid which might lead to tissue damage and may have only moderate beneficial effect compared to placebo, though they had been used very commonly by the public even without prescriptions[11]. Cryotherapy, laser surgery are considered pain free and effective treatment options. Vitamin derivatives in the form of retinoids inhibit cell growth and are considered an effective treatment option. However, surgical excision remains widely practiced and effective cure for these lesions.[6,7] Success rates of $65 \%$ to $85 \%$ have been reported but scarring can be problematic on the sole of foot and face [9].

Frequently similar lesions if left untreated may resolve spontaneously and those that persist should be removed surgically either by routine excision or laser ablation.

The diagnosis of HPV- associated oral lesions is essentially clinical, but histological confirmation is normally recommended. There is a potential for dysplasia in viral papilloma patients with some coexisting morbidity.

\section{CONCLUSION}

Verrucous lesions remain a challenge to diagnose and treat at an early stage. However, with clinical acumen and various modalities available. Dental professionals have three main responsibilities related to HPV and risk reduction:

1. To educate themselves on the appearance of HPV-related signs and symptoms in order to perform more thorough examinations and oral cancer screenings

2. To educate patients on HPV and HPV related cancers, including prevention, vaccination, selfscreening instructions, and treatment
3. To encourage and refer patients to obtain HPV vaccination, particularly for boys and girls aged 11-12.

\section{REFERENCES}

[1] Forman D, de Martel C, Lacey CJ, Soerjomataram I, Lortet-Tieulent J, Bruni L, et al. Global burden of human papillomavirus and related diseases. Vaccine. 2012;30(Suppl 5): F12-23.

[2] Bzhalava D, Guan P, Franceschi S, Dillner J, Clifford G. A systematic review of the prevalence of mucosal and cutaneous human papillomavirus types. Virology. 2013;445(1-2): 224-231.

[3] Szpirglas H., Ben Slama L. Pathologie de la muqueuse buccale. Ed: scientifiques et médicales Elsevier Paris 1999.

[4] Pindborg J.J. Atlas des maladies de la muqueuse buccale. Ed: Masson Paris 1995.

[5] Laskaris G. Atlas des maladies buccales. 2e éd. Ed: Médecine-Sciences Flammarion Paris 1994.

[6] Praetorius F. HPV-associated diseases of oral mucosa. Clin Dermatol 1997;15:399-413.

[7] Denny LA, Franceschi S, de Sanjosé S, Heard I, Moscicki AB, Palefsky J. Human papillomavirus, human immunodeficiency virus and immunosuppression. Vaccine 2012;30 Suppl 5:F168-74.

[8] Joshi M, Shah A, Vishnoi S. Oral verruca vulgaris: report of two rare cases and review. National Journal of Integrated Research in Medicine. 2013 Jul-Aug; 4(4): 145-148.

[9] Atullah JK, Murad N, Khitab U. Oral verruca vulgaris: A rare case with transformation of papilloma to Well Differentiated Oral Squamous Cell Carcinoma. Pakistan Oral \& Dental Journal. 2010 Dec 1;30 (2).

[10] Sarabadani J, Ghanbariha M, Khajehahmadi S, Nehighalehno M. Consistency rates of clinical and histopathologic diagnoses of oral soft tissue exophytic lesions. Journal of dental research, dental clinics, dental prospects. 2009; 3(3):86.

[11] Nucci V, Torchia D, Cappugi P. Condyloma acuminatum of the tongue treated with photodynamic therapy. Clin Infect Dis 2009; 48 (9): 1330-1332.

[12] Lipke MM. An armamentarium of wart treatments. Clin Med Res 2006; 4 (4): 273-293

Citation: Adel Bouguezzi et.al, "Labial Verruca Vulgaris: A Case Report and Review of the Literature", International Journal of Research Studies in Medical and Health Sciences. 2020; 5(5): 45-47.

Copyright: () 2020 Adel Bouguezzi et.al, This is an open-access article distributed under the terms of the Creative Commons Attribution License, which permits unrestricted use, distribution, and reproduction in any medium, provided the original author and source are credited. 